\title{
VIOLÊNCIA OBSTÉTRICA NO BRASIL: UMA REVISÃO BIBLIOGRÁFICA
}

Categoria: Saúde Coletiva/ Epidemiologia

\section{CENTRO UNIVERSITÁRIO SÃO CAMILO}

Paz, $\mathrm{A}^{1}$; Martins, $\mathrm{C}^{1}$; Simplini, $\mathrm{CM}^{1}$; Plum, $\mathrm{JDG}^{1}$; Nascimento, $\mathrm{MCC}^{1}$; Oliveira, $\mathrm{PS}^{1}$; Manso, $\mathrm{MEG}^{2}$

${ }^{1}$ DISCENTES DO CENTRO UNIVERSITÁRIO SÃO CAMILO

2 DOCENTE DE INTRODUÇÃO AO ESTUDO DA MEDICINA DO CENTRO UNIVERSITÁRIO SÃO CAMILO

Primeiro autor: Camila Mendes Simplini

Email - csimplini@gmail.com

Telefone - (11) 99639-0689

Endereço - Rua Duque de Caxias, 244, casa 11 


\title{
VIOLÊNCIA OBSTÉTRICA NO BRASIL: UMA REVISÃO BIBLIOGRÁFICA
}

\author{
Categoria: Saúde Coletiva/ Epidemiologia
}

Descritores: SAÚDE DA MULHER, SAÚDE PÚBLICA, VIOLÊNCIA CONTRA A MULHER, GRAVIDEZ. 


\title{
VIOLÊNCIA OBSTÉTRICA NO BRASIL: UMA REVISÃO BIBLIOGRÁFICA
}

\author{
Paz, A; Martins, C; Simplini, CM; Plum, JDG; Nascimento, MCC; Oliveira, PS - \\ ACADÊMICOS DO CENTO UNIVERSITÁRIO SÃO CAMILO
}

Manso, MEG - DOCENTE DE INTRODUÇÃO AO ESTUDO DA MEDICINA DO CENTRO

UNIVERSITÁRIO SÃO CAMILO

\section{RESUMO:}

INTRODUÇÃO: A violência obstétrica pode ser caracterizada como um tipo específico de violência contra a mulher, de natureza física e psicológica. Com grande prevalência nas maternidades públicas, tal violência se tornou um problema de saúde pública, principalmente pela sua faceta velada e por não ser compreendida pela grande maioria das parturientes vítimas de práticas abusivas e invasivas na hora do parto. Sendo assim, sua conceitualização e discussão torna-se de extrema importância, de forma que mulheres reconheçam práticas irregulares e reivindiquem seu direito como protagonistas do parto.

OBJETIVOS: Esse artigo tem como objetivo realizar uma revisão bibliográfica sobre o tema "Violência Obstétrica no Brasil".

METODOLOGIA: Foi realizada uma revisão da bibliografia publicada sobre violência obstétrica na base de dados BIREME. Usando os seguintes descritores: saúde da mulher, saúde pública, violência contra a mulher, gravidez, violência obstétrica; e restringindo as publicações aos anos de 2015 a 2017 e à adequação ao tema desejado, foram selecionados por fim 6 artigos.

RESULTADOS: Como resultado, os artigos consideram necessárias mudanças nas práticas assistenciais vigentes, com o objetivo de reduzir as intervenções cirúrgicas e medicamentosas desnecessárias durante o parto e acabar com as violações aos direitos das mulheres. Sabe-se, atualmente, que $90 \%$ dos partos e nascimentos transcorrem fisiologicamente de uma gravidez sem risco e sem necessidade de intervenção. Porém, 56\% dos partos, ocorrem por cesárea. Percebe-se, assim, uma incoerência entre a necessidade e a realidade, a qual explicita o emprego de inúmeros procedimentos julgados necessários, mas que desrespeitam os direitos e as seguranças da mulher.

CONCLUSÃO: Concluiu-se que a violência obstétrica se dá de diversas formas, não sendo possível caracterizá-la de uma única maneira. Tal agressão têm sido cada vez mais escancarada, embora ainda aconteça de forma velada e despercebida nas instituições públicas. Dessa forma, a publicação de mais artigos abordando o tema é de extrema importância para um aumento de sua visibilidade e uma consequente mudança no cenário brasileiro atual.

DESCRITORES: Saúde da Mulher, Saúde Pública, Violência Contra a Mulher, Gravidez. 


\section{VIOLÊNCIA OBSTÉTRICA NO BRASIL: UMA REVISÃO BIBLIOGRÁFICA}

\section{INTRODUÇÃO:}

A violência obstétrica foi reconhecida pela Organização Mundial de Saúde (OMS) em 2014, porém tal problema data de muitos anos, aparecendo na mídia pela primeira vez na década de 50, nos Estados Unidos, quando o Ladies Home publicou uma matéria sobre a "Crueldade nas Maternidades", a qual provocou uma grande repercussão entre o público feminino. A revista recebeu grande quantidade de cartas relatando experiências de abuso durante o parto ${ }^{1}$.

No Brasil, a discussão ganhou força somente em 1980, quando surgiram os primeiros movimentos sociais pela humanização do parto e do nascimento. Diversos artigos começaram a ser publicados sobre o tema, sendo o pioneiro o "Espelho de Vênus", do Grupo Cerce, que denunciou a violenta experiencia de um parto institucionalizado, naquela época ${ }^{1}$.

Atualmente, a violência obstétrica prevalece no sistema de saúde público, muitas vezes não compreendida por muitas das mulheres vítimas de práticas abusivas na hora do parto. Tal contexto demonstra a faceta velada da violência obstétrica, vista pelos médicos como uma consequência da falta de estrutura dos hospitais, da precariedade dos serviços e das más condições de trabalho. Percebe-se assim, a importância da conceitualização de violência obstétrica, para que mulheres reconheçam práticas irregulares e reivindiquem seus direitos como protagonistas do parto.

De acordo com a OMS, a violência é a imposição de um grau significativo de dor e sofrimento evitáveis. Assim, pode-se classificar violência obstétrica como um tipo específico de violência contra a mulher, a qual inclui negligencia na assistência, discriminação, violência verbal, física ou sexual, restrição ao leito, manobra de kristeller, episiotomia rotineira, exames de toque repetitivos e dolorosos, tricotomia, amniotomia, lavagem intestinal, utilização de 
medicamentos sem consentimento, abuso de poder, entre outros. É possível classificar, também, a realização de cesárea quando não necessária uma forma de abuso, prática que, no Brasil, atinge $56 \%$, sendo que, pela OMS, a taxa recomendada seria de, no máximo, $15^{\% 2}$.

Tendo em vista o cenário acima, é possível afirmar que a violência obstétrica é um importante tema a ser discutido, uma vez que é frequentemente ocultada pelos profissionais da saúde. A publicação de artigos a respeito do assunto se faz necessária para que mais pessoas tenham a ciência dessa realidade e ajam ativamente afim de mudá-la.

Dentre os estudantes de medicina, a discussão torna-se essencial, considerando que os profissionais da saúde são os principais protagonistas da violência. A soberania de um médico dentro da instituição, muitas vezes, sobrepõe-se ao direito de autonomia da mulher, tornando-a submissa aos procedimentos determinados por ele. Sendo assim, a graduação de medicina deve promover a reflexão do estudante quanto as atuais condições do parto nos hospitais, para que esses não reproduzam nenhum tipo de prática indesejada ou dolorosa, garantindo melhor assistência às puérperas ${ }^{2}$.

Essa revisão bibliográfica tem como objetivo escancarar os tipos de violências obstétricas ainda cometidas em hospitais da rede pública durante os partos, no Brasil, visando, assim, refletir acerca da manutenção de tal problemática e revisar artigos com relatos de experiências das gestantes.

\section{DELINEAMENTO METODOLÓGICO:}

Para confecção desse artigo, seguindo a resolução 510 de 2016, foi utilizada a base de dados Bireme, afim de localizar estudos relevantes ao assunto. Como violência obstétrica não é um descritor, optamos por utilizar os seguintes: violência contra a mulher e saúde da mulher. Com o descritor "Violência contra a mulher", foram encontrados 1324 artigos e ao aplicar o 
filtro "saúde pública", sobraram 51 artigos. Restringindo os artigos aos anos de 2015 e 2016, foram encontrados 7, e desses, 2 foram selecionados pela adequação de seus temas. Já com o descritor "Saúde da mulher", foram encontrados 34.448 artigos. Utilizando o filtro "gravidez" reduzimos esse número para 4161, e ao selecionarmos os do ano de 2017, restaram 4, julgados adequados para participar do artigo.

\section{RESULTADOS:}

\begin{tabular}{|c|c|c|c|c|}
\hline Título & Autores & Método & Resumo & Publicação \\
\hline $\begin{array}{l}\text { O direito ao } \\
\text { acesso e } \\
\text { acompanham } \\
\text { ento ao parto } \\
\text { e nascimento: } \\
\text { A ótica das } \\
\text { mulheres }\end{array}$ & $\begin{array}{l}\text { Angela Mitrano } \\
\text { Perazzini de Sá, } \\
\text { Valdecyr Herdy } \\
\text { Alves, Diego } \\
\text { Pereira } \\
\text { Rodrigues, } \\
\text { Maria Riker } \\
\text { Bertilla } \\
\text { Lutterbach } \\
\text { Branco, Enimar } \\
\text { de Paula, } \\
\text { Giovanna } \\
\text { Rosário Soanno } \\
\text { Marchiori }\end{array}$ & $\begin{array}{l}\text { Estudo descritivo, } \\
\text { exploratório e de } \\
\text { abordagem } \\
\text { qualitativa. } \\
\text { Entrevista com } 28 \\
\text { mulheres de } \\
\text { maternidades } \\
\text { públicas, } \\
\text { submetidas a } \\
\text { entrevistas } \\
\text { semiestruturadas }\end{array}$ & $\begin{array}{l}\text { Analisar a violência } \\
\text { praticada por } \\
\text { profissionais da } \\
\text { saúde durante o } \\
\text { parto ao restringirem } \\
\text { o direito ao } \\
\text { acompanhante para } \\
\text { grávidas. O resultado } \\
\text { observado foi o } \\
\text { descumprimento da } \\
\text { Lei do } \\
\text { Acompanhante. } \\
\text { Concluiu-se que o } \\
\text { apoio à mulher deve } \\
\text { ser garantido por } \\
\text { direitos legais. }\end{array}$ & $\begin{array}{l}\text { Revista de } \\
\text { Enfermagem } \\
\text {, UFPE } \\
\text { online, Jul } \\
2017\end{array}$ \\
\hline $\begin{array}{l}\text { Violência no } \\
\text { parto: } \\
\text { Revisão } \\
\text { integrativa }\end{array}$ & $\begin{array}{l}\text { Clícia Valim } \\
\text { Côrtes Gradim, } \\
\text { Giseli Mendes } \\
\text { Rennó, Michelly } \\
\text { Esteves Ribeiro, } \\
\text { Tânia Carla de } \\
\text { Moraes Prado } \\
\text { Pacheco, } \\
\text { Thamyris } \\
\text { Alexandre } \\
\text { Salles }\end{array}$ & $\begin{array}{l}\text { Revisão } \\
\text { integrativa para } \\
\text { responder qual a } \\
\text { produção } \\
\text { científica } \\
\text { existente acerca } \\
\text { da violência } \\
\text { contra a mulher } \\
\text { no momento do } \\
\text { parto }\end{array}$ & $\begin{array}{l}\text { O resultado foram } 11 \\
\text { estudos sobre o } \\
\text { assunto, sendo } 10 \\
\text { publicados no Brasil. } \\
\text { Todos reconheceram } \\
\text { a violência obstétrica } \\
\text { como um problema e } \\
\text { concluíram que as } \\
\text { mulheres não a } \\
\text { reconhecem, além da } \\
\text { atribuição dos } \\
\text { abusos à condição } \\
\text { insatisfatória do } \\
\text { trabalho e a falta de } \\
\text { estrutura, por parte } \\
\text { dos médicos }\end{array}$ & $\begin{array}{l}\text { Revista de } \\
\text { Enfermagem } \\
\text {, UFPE } \\
\text { online, Mar } \\
2017\end{array}$ \\
\hline $\begin{array}{l}\text { Violência } \\
\text { Obstétrica }\end{array}$ & $\begin{array}{l}\text { Simone Grillo } \\
\text { Diniz, Heloísa }\end{array}$ & $\begin{array}{l}\text { Revisão Crítica- } \\
\text { narrativa que }\end{array}$ & $\begin{array}{l}\text { A violência } \\
\text { obstétrica tornou-se }\end{array}$ & $\begin{array}{l}\text { Journal of } \\
\text { Human }\end{array}$ \\
\hline
\end{tabular}




\begin{tabular}{|c|c|c|c|c|}
\hline $\begin{array}{l}\text { como questão } \\
\text { para a saúde } \\
\text { pública no } \\
\text { Brasil: } \\
\text { Origens, } \\
\text { definições, } \\
\text { tipologia, } \\
\text { impactos } \\
\text { sobre a saúde } \\
\text { materna e } \\
\text { propostas } \\
\text { para sua } \\
\text { intervenção }\end{array}$ & $\begin{array}{l}\text { de Oliveira } \\
\text { Salgado, Halana } \\
\text { Faria de Aguiar } \\
\text { Andrezzo, Paula } \\
\text { Galdino Cardin } \\
\text { de Carvalho, } \\
\text { Priscila } \\
\text { Cavalcanti } \\
\text { Albuquerque } \\
\text { Carvalho, } \\
\text { Cláudia de } \\
\text { Azevedo } \\
\text { Aguiar, Denise } \\
\text { Yoshie Niy }\end{array}$ & $\begin{array}{l}\text { aborda literatura } \\
\text { acadêmica, } \\
\text { produção dos } \\
\text { movimentos } \\
\text { sociais, } \\
\text { documentos } \\
\text { institucionais do } \\
\text { Brasil e exterior }\end{array}$ & $\begin{array}{l}\text { um tema recorrente e } \\
\text { foi reconhecido pela } \\
\text { OMS como um } \\
\text { problema de saúde. } \\
\text { Os autores } \\
\text { mapearam as } \\
\text { origens, tipologia, } \\
\text { definições, impactos } \\
\text { na saúde materna, } \\
\text { proposta de } \\
\text { intervenção e } \\
\text { superação, além de } \\
\text { discutir o papel dos } \\
\text { profissionais da } \\
\text { saúde, bem como a } \\
\text { organização do } \\
\text { sistema público }\end{array}$ & $\begin{array}{l}\text { Growth and } \\
\text { Developmen } \\
\text { t, } 2015\end{array}$ \\
\hline $\begin{array}{l}\text { Percepções } \\
\text { sobre a } \\
\text { violência } \\
\text { obstétrica na } \\
\text { ótica de } \\
\text { puérperas }\end{array}$ & $\begin{array}{l}\text { Mayra de Castro } \\
\text { Oliveira e } \\
\text { Magno } \\
\text { Conceição das } \\
\text { Merces }\end{array}$ & $\begin{array}{l}\text { Estudo descritivo } \\
\text { de abordagem } \\
\text { qualitativa, com } \\
10 \text { puérperas. Os } \\
\text { dados foram } \\
\text { produzidos por } \\
\text { meio de } \\
\text { entrevistas } \\
\text { semiestruturadas } \\
\text { e analisados pela } \\
\text { Técnica de } \\
\text { Análise de } \\
\text { Conteúdo na } \\
\text { modalidade } \\
\text { Análise } \\
\text { Categorial. }\end{array}$ & $\begin{array}{l}\text { O artigo tem como } \\
\text { objetivo conhecer a } \\
\text { percepção das } \\
\text { puérperas a respeito } \\
\text { da violência } \\
\text { obstétrica, obtendo } \\
\text { como resultados } \\
\text { duas perspectivas: } \\
\text { Muitas mulheres têm } \\
\text { sua percepção } \\
\text { restringida, não } \\
\text { reconhecendo a } \\
\text { violência e também a } \\
\text { violência velada } \\
\text { presente na hora do } \\
\text { parto. }\end{array}$ & $\begin{array}{l}\text { Revista de } \\
\text { Enfermagem } \\
\text {, UFPE } \\
\text { online, Jun } \\
2017\end{array}$ \\
\hline $\begin{array}{l}\text { Relato de } \\
\text { Puérperas } \\
\text { acerca da } \\
\text { violência } \\
\text { obstétrica nos } \\
\text { serviços } \\
\text { públicos }\end{array}$ & $\begin{array}{l}\text { Laís Chaves do } \\
\text { Nascimento, } \\
\text { Kamyla Felix } \\
\text { Oliveira dos } \\
\text { Santos, Cristiani } \\
\text { Garrido de } \\
\text { Andrade }\end{array}$ & $\begin{array}{l}\text { Estudo } \\
\text { exploratório } \\
\text { descritivo com } \\
\text { abordagem } \\
\text { qualitativo } \\
\text { realizado com } 41 \\
\text { puérperas nas } \\
\text { unidades de saúde } \\
\text { da família. Os } \\
\text { dados foram } \\
\text { produzidos por } \\
\text { meio de } \\
\text { entrevistas e } \\
\text { submetidos à } \\
\text { técnica de análise } \\
\text { de conteúdo na }\end{array}$ & $\begin{array}{l}\text { Objetivo foi expor as } \\
\text { formas de violência } \\
\text { obstétricas sofridas } \\
\text { durante a gestação e } \\
\text { o parto, a partir de } \\
\text { relatos de puérperas. } \\
\text { Como resultado, foi } \\
\text { obtido as seguintes } \\
\text { categorias temáticas: } \\
\text { tipos de violência } \\
\text { obstétrica } \\
\text { vivenciadas na } \\
\text { gestação e no parto e } \\
\text { as repercussões da } \\
\text { violência obstétrica } \\
\text { na vida das mulheres } \\
\text { e os principais }\end{array}$ & $\begin{array}{l}\text { Revista de } \\
\text { Enfermagem } \\
\text {, UFPE } \\
\text { online, mai } \\
2017\end{array}$ \\
\hline
\end{tabular}




\begin{tabular}{|c|c|c|c|c|}
\hline & & $\begin{array}{l}\text { modalidade de } \\
\text { análise temática }\end{array}$ & $\begin{array}{l}\text { profissionais } \\
\text { envolvidos. Logo, } \\
\text { conclui-se que as } \\
\text { principais formas de } \\
\text { violência obstétrica } \\
\text { são: Dor, Exames } \\
\text { abusivos repetitivos, } \\
\text { Manobras sem } \\
\text { evidências } \\
\text { científicas de } \\
\text { qualquer benefício e } \\
\text { o descaso. }\end{array}$ & \\
\hline $\begin{array}{l}\text { Violência } \\
\text { obstétrica no } \\
\text { Brasil: Uma } \\
\text { revisão } \\
\text { narrativa }\end{array}$ & $\begin{array}{l}\text { Gabriela Lemos } \\
\text { de Pinho } \\
\text { Zanardo, } \\
\text { Magaly } \\
\text { Calderon Uribe, } \\
\text { Ana Hertzog } \\
\text { Ramos de Nadal }\end{array}$ & $\begin{array}{l}\text { Abordou-se o } \\
\text { histórico do parto } \\
\text { e suas } \\
\text { intervenções, o } \\
\text { conceito de } \\
\text { violência } \\
\text { obstétrica, os } \\
\text { marcos legais e o } \\
\text { panorama } \\
\text { brasileiro de } \\
\text { assistência ao } \\
\text { parto. }\end{array}$ & $\begin{array}{l}\text { Este artigo teve } \\
\text { como objetivo } \\
\text { realizar uma revisão } \\
\text { narrativa de estudos } \\
\text { sobre a violência } \\
\text { obstétrica. Após a } \\
\text { revisão das } \\
\text { pesquisas, percebeu- } \\
\text { se que não há } \\
\text { consenso ao conceito } \\
\text { de violência } \\
\text { obstétrica no Brasil, } \\
\text { embora as } \\
\text { evidências indiquem } \\
\text { que essa prática } \\
\text { ocorra. Os dados } \\
\text { indicam a } \\
\text { necessidade de uma } \\
\text { conceituação de } \\
\text { violência obstétrica, } \\
\text { preferencialmente } \\
\text { em documentos } \\
\text { legais que a definam } \\
\text { e a criminalizem. }\end{array}$ & $\begin{array}{l}\text { Psicologia e } \\
\text { Sociedade, } \\
\text { volume } 29 .\end{array}$ \\
\hline
\end{tabular}

Quadro: Artigos selecionados na pesquisa com a base de dados BIREME.

\section{DISCUSSÃO:}

Antigamente, o parto ocorria, majoritariamente, em ambiente domiciliar, conduzido principalmente por parteiras, curandeiras e comadres. Apesar de não dominarem o saber científico, as auxiliares eram dotadas de experiência e respeitavam o processo fisiológico do nascimento, mantendo a mulher como foco durante o processo. Com o passar dos anos e com 
a incorporação da tecnologia aos ambientes hospitalares, o parto tornou-se um evento médico e patológico. Ou seja, o que era exceção, tornou-se regra e as intervenções médicas passaram a ser rotina. Dessa forma, o saber da medicina começou a imperar sobre as vontades da mulher e o médico tornou-se protagonista ${ }^{1}$.

Sabe-se, atualmente, que $90 \%$ dos partos e nascimentos transcorrem fisiologicamente de uma gravidez sem risco e sem necessidade de intervenção. Porém, $56 \%$ dos partos, ocorrem por cesárea ${ }^{2}$. Percebe-se, assim, uma incoerência entre a necessidade e a realidade, a qual explicita o emprego de inúmeros procedimentos julgados necessários, mas que desrespeitam os direitos e as seguranças da mulher. Sendo assim, a relação médico-parturiente, que deveria ser humanizada, torna-se abusiva e violenta.

No entanto, a cesárea realizada sem necessidade é apenas uma das diversas formas de violência obstétrica. Tal forma de violência é multifatorial e pode ser caracterizada como uma apropriação do corpo da mulher e de seu processo partutivo, tornando-o degradante de diversas formas. Com isso, o parto passa a ser visto como uma situação de medo e risco à vida, centrado totalmente na dor. Dessa forma, a cesárea é apresentada pelos médicos como uma via de escape e de proteção da dignidade da mulher, evitando um possível constrangimento. Configura-se, então, uma forma de violência velada, uma vez que $23 \%$ das taxas de mortalidade materna podem ser atribuídas apenas ao aumento nas taxas de cesárea ocorrido desde $2000^{2}$.

Não é possível definir uma única violência obstétrica, uma vez que essa é praticada por múltiplos agentes, como enfermeiros, médicos, técnicos de enfermagem, entre outros, afetando a mulher de maneiras distintas, sendo elas física, verbal e psicologicamente. No entanto, em uma entrevista realizada com 10 mulheres que utilizavam a rede pública do Centro-Sul de Salvador, Bahia, em 2015, mostrou que nenhuma delas estava familiarizada com o termo "violência obstétrica" e, apesar de relatarem os abusos em seus discursos, não reconheciam ter 
vivenciado tal agressão e consideravam práticas abusivas como "natural" do processo parturiente ${ }^{3}$.

"Acho que eles não quer me ver lá tão cedo, eu sei que depois que as dores aumentou, assim umas duas horas, eu não queria deitar na cama e levantei para tomar banho. Aí do meio pro fim a enfermeira gritou comigo: você caga, você mija na cama, mas você não levanta mais para nada que o menino já tá perto de nascer..."3(E10)

Uma realidade nos serviços de saúde é a cultura do silenciamento. As mulheres já chegam na maternidade com a noção de que devem se calar diante da dor, caso não queiram ser negligenciadas. Acredita-se que mulheres que demonstram a dor e são consideradas "malcomportadas" são frequentemente destratadas e sofrem do descaso dos profissionais de saúde. Em uma pesquisa feita no município de Cabedelo, na Paraíba, em 2012, esse cenário é reafirmado em diversos relatos ${ }^{3}$.

"Eu só fazia chorar, por que o povo diz que quando faz escândalo, eles deixam sofrer mais. Aí fiquei só na minha, andando e chorando baixo. Só não fazia escândalo ${ }^{3}$."

O quadro abaixo mostra os diferentes tipos de violência praticados no meio obstétrico: 


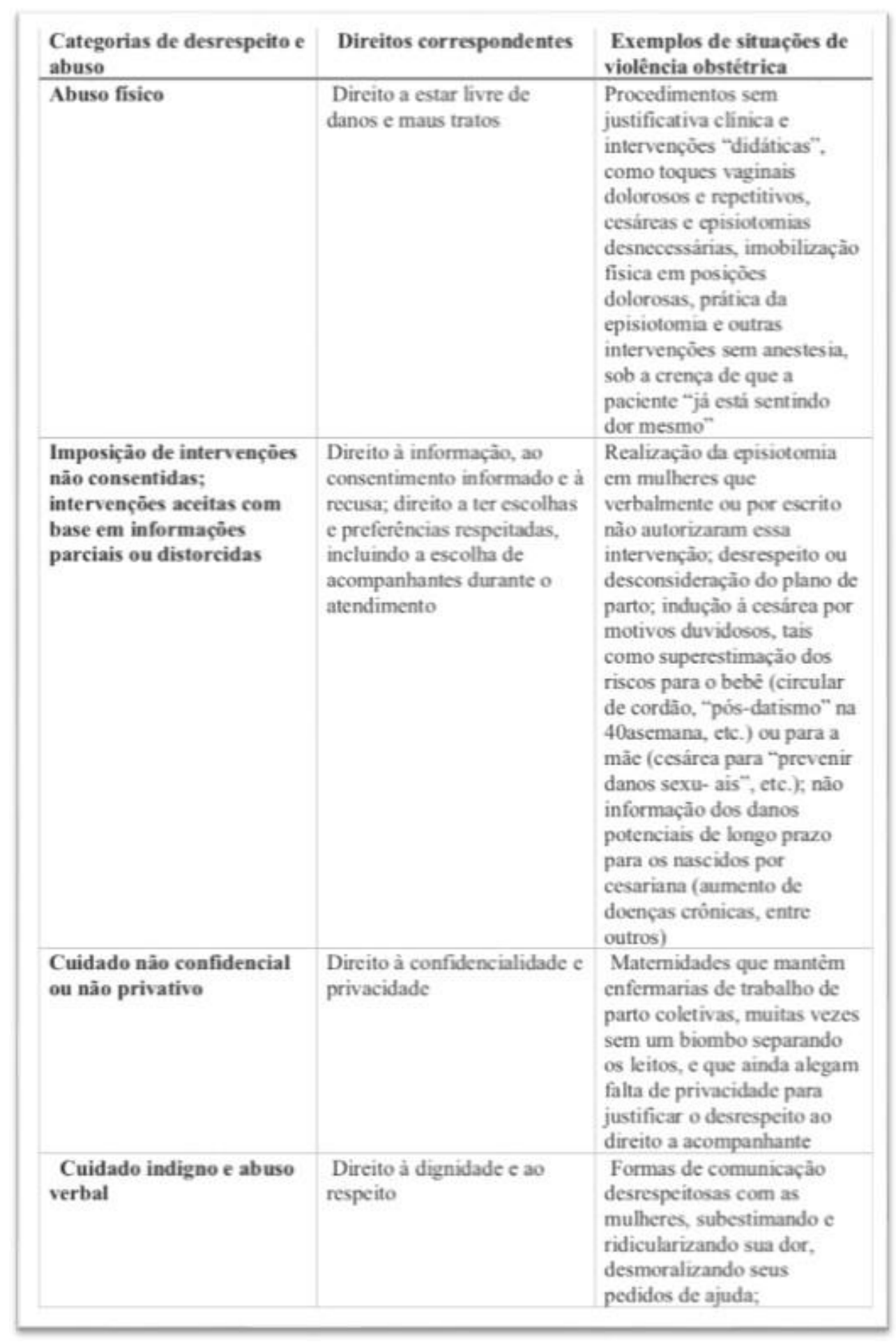

Quadro: Categorias de desrespeitoeabuso, direitos correspondentes eexemplos desituações de violência obstétrica. Fonte: Tesser et al (2015).

As escolas de medicina utilizam materiais didáticos ultrapassados e muitas vezes não promovem uma educação humanizada. Com isso, manobras que não possuem evidências 
científicas e que já estão ultrapassadas continuam sendo utilizadas, oferecendo riscos às parturientes e aos bebês. Dentre tais manobras, pode-se citar a Manobra de Kristeller, Episiotomia, Tricotomia, Amniotopima e o uso do Fórceps. Além disso, exames de toques repetitivos, uso rotineiro de ocitocina, interdição à movimentação, privação de alimento, ameaças verbais também são muito praticados, configurando formas de violência 4 .

É importante ressaltar que $25 \%$ das mulheres sofrem violência no processo parturitivo e que $74 \%$ dessas acontecem em maternidades públicas ${ }^{1}$. As frequentes violações dos direitos humanos das mulheres tornaram-se parte da rotina e não causam mais estranhamento. De acordo com o Ministério Público, a área da obstetrícia é a que mais comete infrações. Diante disso, já é possível observar pequenas mudanças na tentativa de reverter esse cenário, com o objetivo de promover um atendimento mais humanitário e reduzir o número de intervenções desnecessárias.

Em 2002, através da Portaria/GM, n56, de 2000, foi estabelecido o programa de prénatal e nascimento (PHPN) que tem como objetivo garantir a melhoria do acesso, da cobertura e da qualidade e do acompanhamento pré natal, da assistência ao parto, às gestantes e ao recémnascido. Foi criada, também, uma política nacional de humanização (PNH), em 2003, a qual enfatiza a autonomia, o protagonismo, a corresponsabilidade e o estabelecimento de vínculos solidários e a participação coletiva entre os usuários, trabalhadores e gestores da rede pública 5 .

Já a lei do acompanhante, nº11.108/2005, garante às gestantes o direito irrevogável da presença de um acompanhante de sua escolha durante todo o processo de parto. A rede cegonha é outra estratégia que pretende garantir à mulher vagas na rede pública para que sua gestação e parto sejam acompanhados e devidamente assistidos, além de promover o encaminhamento adequado em caso de lotação da unidade obstétrica ${ }^{5}$. 
Embora tais medidas já estejam em prática e melhorem o respaldo legal da gestante e parturiente, é possível concluir que a violação dos direitos e a negligência no atendimento ainda são uma realidade, no Brasil. Tal realidade ainda é omitida e mascarada nas instituições, o que faz com que a discussão no meio acadêmico, por meio de publicações de artigos e debates, à respeito da violência obstétrica seja essencial.

\section{CONCLUSÃO:}

Com base na discussão acima, é possível concluir que a violência obstétrica se dá de diversas formas, não sendo possível caracterizá-la de única maneira. Tal agressão têm sido cada vez mais escancarada, embora ainda aconteça de forma velada e despercebida nas instituições públicas.

Com as medidas legais sendo tomadas e a mobilização do Ministério Público, as parturientes e gestantes estão progressivamente ganhando visibilidade e voz para relatar os abusos experienciados. É de extrema importância a publicação do assunto em meio acadêmico, para que haja a repercussão necessária e a reflexão dos profissionais de saúde acerca dos métodos ditos "tradicionais", mas que acabam por violar direitos.

É possível ainda destacar o desconhecimento da violência obstétrica por parte de mulheres usuárias da rede pública que consideram as agressões como "naturais" do processo parturiente por desconhecerem seu direito de escolha e de autonomia.

\section{REFERÊNCIAS:}

1.ZANARDO, Gabriela Lemos de Pinho et al. VIOLÊNCIA OBSTÉTRICA NO BRASIL: UMA REVISÃO NARRATIVA. Psicologia \& Sociedade, Porto Alegre, v. 29, n. 1, p.1-11, jan. 2017. 
2.GRADIM, Clínica Valim Côrtes et al. Violência no parto: revisão integrativa. Revista de Enfermagem UFPE On Line, Recife, v. 1, n. 1, p.1-11, mar. 2017

3.OLIVEIRA, Mayra de Castro; MERCES, Magno Conceição das. Percepções sobre violências obstétricas na ótica de puérperas. Revista de Enfermagem UFPE On Line, Recife, v. 1, n. 1, p.1-7, jul. 2017.

4.DINIZ, Simone Grilo et al. VIOLÊNCIA OBSTÉTRICA COMO QUESTÃO PARA A SAÚDE PÚBLICA NO BRASIL: ORIGENS, DEFINIÇÕES, TIPOLOGIA, IMPACTOS SOBRE A SAÚDE MATERNA, E PROPOSTAS PARA SUA PREVENÇÃO. Revista Brasileira de Desenvolvimento Humano, São Paulo, v. 1, n. 1, p.1-8, jan. 2015.

5.NASCIMENTO, Lais Chaves do et al. Relato de puérperas acerca da violência obstétrica nos serviços públicos. Revista de Enfermagem UFPE On Line, Recife, v. 1, n. 1, p.1-8, maio 2017. 